\title{
SUPERVISI AKADEMIK PENGAWAS SEKOLAH DALAM MENINGKATKAN PROFESIONALISME GURU DI MASA PANDEMICOVID-19 TAHUN 2020/2021
}

\section{ACADEMIC SUPERVISION OF SCHOOL SUPERVISORS IN IMPROVING TEACHERS PROFESSIONALISM DURING COVID-19 PANDEMIC 2020/2021}

\author{
SUDARMAN HS
}

Suku Dinas Pendidikan Wilayah II Pemerintah Daerah Jakarta Pusat

\begin{abstract}
Received: March 09, 2021 This research was motivated by the low professionalism of teachers SMPN 228 Jakarta during Revised: September 30, 2021 Covid-19 Pandemic. The purpose of this study to improve teachers professionalism of SMPN Accepted: November 26, 2021228 Jakarta during Covid-19 pandemic. This research is a school action research (PTS) which is conducted through socialization through the Teacher Working Group (KKG). Design of this study uses a non-directive supervision model, which consists of four stages, namely: planning, action, observation and reflection. Data analysis technique was carried out in a descriptive qualitative manner. Results of this study indicate that teachers professionalism of SMPN 228 Jakarta during Covid-19 pandemic has increased, namely from the results of academic supervision carried-out on teachers of SMPN 228 Jakarta there is an increase in teacher professionalism in online learning. Teachers in previous learning still have difficulty adapting to online learning, after coaching and supervision, teachers are used to developing their professionalism in online learning
\end{abstract}

\begin{abstract}
Abstrak. Penelitian ini didasari oleh masih kurangnya profesionalisme guru SMPN 228 Jakarta di masa Pandemi Covid-19. Tujuan penelitian ini adalah untuk meningkatkan profesional guru SMPN 228 Jakarta di masa pandemi covid-19. Penelitian ini ialah Penelitian Tindakan Sekolah (PTS) yang dilaksanakan secara sosialisasi melalui Kelompok Kerja Guru (KKG). Desain penelitian ini menggunakan model supervise Non Direktif, yang terdiri dari 4 tahapan, yaitu: planning (Rencana), action (tindakan), observasi (pengamatan) dan reflection (refleksi). Teknik analisis data dilakukan secara deskriptif kualitatif. Hasil dari penelitian ini menunjukan bahwa profesionalisme guru SMPN 228 Jakarta di masa pandemic covid-19 mengalami peningkatan, yaitu dari hasil supervisi akademik yang dilakukan pada guru SMP Negeri 228 Jakarta terdapat peningkatan profesionalisme guru dalam pembelajaran khususnya pembelajaran daring. Guru pada pembelajaran sebelumnya masih mengalami kesulitan dalam berdaptasi dengan pembelajaran model daring atau pembelajaran jarak jauh, setelah dilakukan pembinaan dan pengawasan oleh pengawas sekolah guru sudah terbiasa dalam mengembangkan profesionalismenya dalam pembelajaran daring
\end{abstract}

Keywords: Teacher professionalism, Covid-19 Pandemic, Online Learning Kata kunci: $\quad$ Profesionalisme Guru, Pandemi Covid-19, Pembelajaran Daring

$\left(^{\star}\right)$ Corresponding Author: jeparasudarman@gmail.com

How to Cite: Sudarman, H.S., (2021). Supervisi Akademik Pengawas Sekolah Dalam Meningkatkan Profesionalisme Guru Di Masa Pandemi Covid-19 Tahun 2020/2021. Jurnal Lingkar Mutu Pendidikan, 18 (2), 227-231. https://doi.org/10.54124/jlmp.v18i1.35

\section{PENDAHULUAN}

Perubahan sosial budaya masyarakat, dapat dikatakan sebagai sebuah akselerasi pertumbuhan ilmu pengetahuan dan teknologi, serta berkembangnya tuntutan mengenai pendidikan yang semakin berkualitas, adalah persoalan yang sedang dan selalu dihadapi oleh satuan pendidikan saat melaksanakan tugasnya menjadi pelaksana pendidikan formal. Keadaan ini berhubungan dengan belajar dan pembelajaran sebagai kunci aktivitas pembelajaran di sekolah. Oleh karena itu wajib diberikan perhatian yang sungguh-sungguh dengan cara memperbaiki dan meningkatkan mutu pendidikan di sekolah secara terus menerus.

Beraneka ragam persoalan yang dihadapi oleh sekolah selaku lembaga pendidikan mengharuskan satuan pendidikan melakukan introspeksi mengenai peran dan kinerjanya dalam pendidikan siswa, 
apa saja cara yang akan digunakan untuk meningkatkan program sekolah yang lebih baik, kreatif, serta lebih inovatif. Perbaikan, pengembangan dan peningkatan mutu pendidikan sekolah membutuhkan sinergi dari seluruh stakeholder sekolah untuk mendukung terwujudnya sebuah proses belajar mengajar yang efektif.

Tujuan dari Pendidikan Nasional berdasarkan Undang-Undang Nomor 20 Tahun 2003 Pasal 3 mengenai Sistem Pendidikan Nasional ialah "Meningkatkan kemampuan siswa supaya menjadi manusia yang mempunyai keimanan dan ketakwaan pada Tuhan Yang Maha Esa, berakhlak mulia, sehat, berilmu, cakap, kreatif, mandiri, dan menjadi warga negara yang demokratis serta mempunyai tanggung jawab". Pihak-pihak yang bertanggung jawab atas terwujudnya tujuan tersebut ialah mereka yang bertemu secara tatap muka dengan siswa di sekolah yaitu guru dan kepala sekolah.

Kualitas proses pembelajaran sangat dipengaruhi oleh kualitas kinerja guru terutama dalam kondisi pandemi Covid-19 seperti ini proses belajar mengajar dilaksanakan melalui daring. Para kepala sekolah dan pengawas di tingkat kantor dinas pendidikan di lingkungan wilayah kerja yang merupakan tanggung jawabnya telah berupaya melakukan pemantauan terhadap kualitas kinerja guru di satuan pendidikan Pengawas perlu memberikan perhatian secara kontinyu kepada guru dalam hal mengembangkan kompetensi guru saat melakukan aktivitas pembelajaran. Keadaan seperti ini dapat berjalan dengan baik bila guru melakukannya dengan kemampuan dan usaha para guru sendiri.

Dalam usaha mengembangkan profesionalisme guru yang berdampak kepada peningkatan mutu dan kualitas pendidikan pengawas memiliki peranan yang sangat penting dan strategis. Daryanto mengemukakan bahwasannya pengawas tidak saja mampu mengarahkan dan memberikan pandangan mengenai bagaimana proses profesionalisme guru dapat dikembangkan (Daryanto, 2009: 253). Selain itu dengan pengalaman yang cukup lama terjun di dunia pendidikan pengawas dapat memperkirakan sesuatu yang bisa timbul bila guru kurang cermat dalam menyelenggarakan sebuah aktivitas belajar mengajar jarak jauh terutama dalam meningkatkan mutu dan kualitas satuan pendidikan binaannya (Sardiman, 2020: 22)

Supervisi rutin yang dilakukan oleh pengawas hanya untuk mengecek kelengkapan administrasi sekolah dan pelaksanaan aktivitas rutin oleh pengajar serta kondisi fisik sekolah supaya sesuai dengan pedoman yang telah ditetapkan. Pengawas akan memberikan saran bila ternyata kurang lengkap dan tidak sesuai dengan pedoman baku agar direvisi oleh kepala sekolah. Salah satu motivasi supaya guru dapat menciptakan dan berproduktivitas tinggi dalam membuat suatu kondisi belajar mengajar yang cukup mengasyikkan terlebih lagi di saat pandemi covid-19 adalah dilakukannya pembinaan. Namun pembinaan dan bimbingan yang sungguh-sungguh kepada tiap individu guru belum sepenuhnya dilaksanakan oleh pengawas, sekolah masih tidak terbiasa saat menyelenggarakan pembelajaran secara daring.

Dalam melakukan sebuah tugas pembinaan, pemantauan, penilaian dan pembimbingan dan pelatihan terhadap pengajar di satuan pendidikan, salah satunya adalah SMP Negeri 228 yang merupakan sekolah di wilayah binaan. Dari pengamatan awal telah didapatkan bahwa tingkat profesionalisme guru di SMP Negeri 228 Jakarta masih jauh dari maksimal, hal ini terlihat dari rendahnya kreatifitas dan ekspresi pendidik atau guru saat memakai gambaran metode pembelajaran daring yang bisa meningkatkan minat belajar siswa.

Oleh sebab itu, guru seharusnya mendapat penyegaran dalam bentuk bantuan teknis agar dapat melaksanakan pekerjaan yang menjadi kewajibannya di sekolah. Sebagai upaya peningkatan kapasitas, bantuan teknis ini diberikan kepada guru secara kontinyu. Bantuan yang diberikan berbentuk pelaksanaan supervisi akademik yang dilaksanakan oleh pengawas adalah salah satu cara menyampaikan bantuan pembinaan dan perubahan prestasi kerja guru supaya bisa mewujudkan tujuan pendidikan nasional (Sudjana \& Dharma, 2011: 56).

Usman (Usman, 2002: 12) menyatakan bahwa supervisi akademik ialah supervisi yang memfokuskan kepada pengendalian dan pembinaan bidang akademik melalui aktivitas belajar mengajar di satuan pendidikan supaya hasil belajar siswa dapat meningkat. Supervisi akademik ialah aktivitas pengawasan yang difokuskan untuk merubah ke arah lebih baik beraneka ragam permasalahan pada proses belajar mengajar sebagai cara agar kualitas dari proses belajar mengajar lebih baik dengan cara pemberian motivasi, pemberian bimbingan dan pembinaan serta pengarahan 
kepada pengajar yang berhubungan dengan aktivitas akademik yang berdampak kepada sebuah peningkatan profesionalisme guru.

Oleh sebab itu dilakukanlah penelitian tentang "Supervisi Akademik Pengawas Sekolah Dalam Meningkatkan Profesionalisme Guru Di Masa Pandemi Covid-19 2020/2021". Penelitian ini dilaksanakan oleh pengawas sekolah sebagai usaha meningkatkan profesionalisme guru di SMPN 228 Jakarta.

\section{METODE PENELITIAN}

Pendekatan yang dipakai pada penelitian ini yaitu penelitian kualitatif, penelitian ini disebut juga metode penelitian yang bersifat natural atau apa adanya, karena pada dasarnya penelitian dilaksanakan pada situasi dan keadaan yang alami (Sugiyono, 2015: 8). Selanjutnya Sugiyono mengemukakan bahwa cara ilmiah untuk memperoleh data dengan maksud dan tujuan tertentu disebut metode penelitian (Sugiyono, 2015: 2).

Penelitian ini memakai teknik pengumpulan data yang bersifat triangulasi, yaitu memakai beraneka ragam teknik pengumpulan data secara gabungan. Lalu Miles dan Huberman mengemukakan bahwa data reduction, data display, dan conclusion drawing or verification adalah aktifitas dalam analisis data (Sugiyono, 2011: 246). Adapun objek penelitian ini yaitu guru SMP Negeri 228 Jakarta yang dipilih sesuai dengan tekniknya.

Penelitian ini dilakukan di SMPN 228 Jakarta yang beralamat di Jalan Sumur Batu Raya No. 6 Kemayoran, Jakarta Pusat. Dengan jadwal penelitian yang dilakukan meliputi kegiatan persiapan penelitian, observasi awal, pengumpulan data, pelaksanaan penelitian, dan penyusunan laporan. Jadwal pelaksanaan penelitian dimulai bulan Juli 2020 sampai dengan bulan Maret 2021.

\section{HASIL DAN PEMBAHASAN}

Bersumber pada hasil observasi awal penelitian yang dilaksanakan di SMP Negeri 228 Jakarta, didapat hasil dari 41 guru yang diamati secara acak oleh kepala sekolah dan pengawas yang sudah menunjukan prestasi kerja saat melakukan proses belajar mengajar sudah menunjukan kinerja yang cukup memuaskan. Kondisi tersebut dipengaruhi oleh keadaan belum terbiasanya dari guru saat melakukan proses belajar mengajar secara online atau PJJ.

Sesuai dengan hasil diatas maka dilakukan penelitian tindakan sekolah melalui supervisi akademik pada 2 pengajar dari SMPN 228 Jakarta. Langkah identifikasi dilaksanakan melalui upaya memakai data hasil supervisi akademik diantaranya perencanaan pembelajaran pada bulan November dan Desember 2020.

Dalam proses peningkatan profesionalisme guru diantaranya dilakukan dengan supervisi akademik yang dilakukan oleh pengawas sekolah. Begitupun yang dilakukan di SMP Negeri 228 Jakarta, yaitu melakukan supervisi akademik terhadap dua orang guru yang ditunjuk sebagai sampel dalam penelitian ini. Adapun kegiatan dalam upaya untuk meningkatkan profesionalisme guru dilakukan dalam dua siklus penelitian.

Ada empat fungsi manajemen yang dirumuskan oleh Robbins, Stephen P., and Coulter, M yaitu perencanaan (planning), penataan (organizing), kepemimpinan (leading), dan pengendalian (controlling). Ada beberapa proses dalam fungsi pengendalian proses yaitu pengawasan, penilaian (evaluasi), dan koreksi. Di dunia pendidikan semua fungsi manajemen ini dilaksanakan oleh kepala sekolah dan pengawas sekolah (Robbins \& Coulter, 2010: 9).

Penelitian ini selanjutnya akan menguraikan mengenai pengawasan yang dilaksanakan oleh pengawas sekolah. Setelah dilaksanakan proses siklus I kepada Ibu Titin Maryamah, S.Pd sebagai Guru Bahasa Indonesia dan Bapak Fahmi Aprizal, S.Pd sebagai Guru Penjasorkes maka diperoleh hasil yaitu:

Tabel 1. Hasil Pelaksanaan Supervisi Akademik Siklus I

\begin{tabular}{ccccc}
\hline NO & KEGIATAN & MATA PELAJARAN & RATA-RATA & KATEGORI \\
\hline 1 & Siklus I & Bahasa Indonesia & $62,5 \%$ & CUKUP \\
2 & Siklus I & Penjasorkes & $60,8 \%$ & CUKUP \\
\hline
\end{tabular}


Berdasarkan tabel di atas diperoleh bahwa pelaksanaan supervisi akademik siklus I di mata pelajaran Bahasa Indonesia rata-rata sebesar 62,5\% sedangkan pada mata pelajaran Penjasorkes lebih mendapatkan rata-rata sebesar 60,8 \%. Artinya kemampuan guru dalam kegiatan belajar mengajar setelah dilaksanakan supervisi akademik pada siklus I dikatakan memiliki kategori cukup.

Kemudian dilaksanakan proses siklus II kepada Ibu Titin Maryamah, S.Pd sebagai Guru Bahasa Indonesia dan Bapak Fahmi Aprizal, S.Pd sebagai Guru Penjasorkes diperoleh hasil yaitu:

Tabel 2. Hasil Pelaksanaan Supervisi Akademik Siklus II

\begin{tabular}{ccccc}
\hline NO & KEGIATAN & MATA PELAJARAN & RATA-RATA & KATEGORI \\
\hline 1 & Siklus II & Bahasa Indonesia & $89,1 \%$ & BAIK SEKALI \\
2 & Siklus II & Penjasorkes & $85 \%$ & BAIK \\
\hline
\end{tabular}

Sesuai tabel di atas diperoleh bahwa pelaksanaan supervisi akademik siklus II di mata pelajaran Bahasa Indonesia rata-rata sebesar $89,1 \%$ sedangkan pada mata pelajaran Penjasorkes lebih mendapatkan rata-rata sebesar $85 \%$. Artinya kemampuan guru dalam proses pembelajaran setelah dilaksanakan supervisi akademik pada siklus II dikatakan memiliki kategori baik sekali di mata pelajaran Bahasa Indonesia dan kategori baik di mata pelajaran Penjasorkes.

Gejala dalam kegiatan belajar mengajar yang belum menginspirasi, mengasyikkan dan memberikan tantangan belum memotivasi siswa dalam berperan aktif, siswa kekurangan ruang prakarsa, kreatif, dan kemandirian sejalan dengan perkembangan bakat, minat, dan psikologi siswa di SMPN 228 Jakarta.

Dalam pelaksanaannya supervisi sebaiknya meliputi berbagai hal diantaranya mengecek kelengkapan administrasi dan berkunjung ke kelas lalu diadakan pertemuan tindakan saat supervisi telah selesai. Sehubungan dengan hal itu pengawas SMP dalam implementasinya hanya mengecek kelengkapan administrasi guru. Kunjungan kelas belum dilaksanakan dengan adil, akibatnya belum seluruh pengajar yang menerima pembinaan dan pembimbingan langsung dari pengawas. Pernyataan ini sesuai dengan yang diutarakan oleh pengawas Sekolah Menengah Pertama yaitu: Sering ditanyakan mengenai administrasi guru contohnya apakah RPP telah diselesaikan dan untuk kunjungan kelas daring hanya segelintir guru.

Berdasarkan dari hasil observasi yang dilakukan terhadap Ibu Titin Maryamah, S.Pd sebagai Guru Bahasa Indonesia dan Bapak Fahmi Aprizal, S.Pd sebagai Guru Penjasorkes, terlihat bahwa guru masih terdapat kendala dalam mendidik dan membimbing siswa, apalagi dalam PJJ atau daring yang masih dalam tahap adaptasi mengakibatkan guru sulit untuk memaksimalkan proses mendidik dan membimbing siswa. Perlu adanya sinergi antara pengawas sekolah, kepala sekolah dan guru-guru dalam menyusun strategi dalam pembelajaran jarak jauh agar mendapatkan hasil yang maksimal.

Peran serta pengawas pada kegiatan pembelajaran bukan hanya memeriksa kelengkapan administrasi untuk pembelajaran guru semata, namun pengawas juga harus memberikan bimbingan dan pemantauan pada kegiatan pembelajaran (Sagala, 2010: 281). Sehingga peran serta pengawas dapat membantu guru dalam membantu meningkatkan profesionalismenya. Peran guru di dunia pendidikan mempunyai peran strategis dan menjadi kunci berhasilnya pendidikan.

Oleh sebab itu, untuk menaikkan kualitas pendidikan perlu difokuskan kepada peningkatan kualitas pengajarnya. Salah satunya ialah melalui peningkatan profesionalisme guru diantaranya aspek perilaku atau keahlian lainnya. Oleh karena itu dibutuhkan beberapa syarat agar menjadi guru profesional, antara lain: mempunyai kualifikasi akademik, mempunyai keahlian, mempunyai sertifikat pendidik, sehat jasmani dan kompetensi untuk mencapai tujuan pendidikan nasional.

Berdasarkan wawancara dengan guru di Sekolah Menengah Pertama Negeri 228 Jakarta, ketika melakukan kunjungan kelas pembelajaran jarak jauh pengawas melakukannya dengan tanpa pemberitahuan terlebih dahulu. Setelah pengawas memeriksa kelengkapan administrasi guru seperti RPP, Program Semester atau Program Tahunan dan kelengkapan lainnya, yang dilakukan pengawas adalah melihat kondisi kelas daring saat melakukan sebuah kegiatan pembelajaran.

Dalam sebuah proses pembimbingan guru dalam kegiatan pembelajaran, guru diminta oleh pengawas untuk menyampaikan kendala-kendala dalam menyusun administrasi guru dan proses 
pembelajaran daring yang dilaksanakan dalam pandemi Covid-19. Berdasarkan hasil wawancara terhadap guru-guru yang dibimbing, terdapat beberapa permasalahan yang perlu dibantu dan dibina olehpengawas, salah satunya adalah mengembangan profesionalisme guru dalam menyusun sebuah pembelajaran yang menarik dimasa pandemi Covid-19.

Supervisiakademik yang dilaksanakan bisa mengembangkan kompetensi guru saat mempersiapkan RPP dan melangsungkan kegiatan belajar mengajar selaras dengan Permendiknas No. 41 Tahun 2007. Pendekatan kolaboratif dalam kegiatan kelompok kerja guru dan dilaksanakan dengan saling bertukar pikiran dan pengalaman sesama guru, dengan pembina dari pengawas sekolah merupakan proses pembelajaran yang dilakukan melalui supervisi akademik.

Supervisi akademik yang ditunjuk dalam penelitian ini dengan aktivitas memberikan binaan dapat meningkatkan kompetensi menyusun RPP dan melakukan kegiatan belajar mengajar agar dengan kesadaran mereka akan memperbaiki dan menyempurnakan tugas utamanya sebagai agen pembelajar. Supervisi akademik dapat juga meningkatkan profesionalisme guru terutama dalam menghadapi tantangan pada kegiatan belajar mengajar secara online yang diselenggarakan saat pandemi Covid-19.

\section{SIMPULAN DAN SARAN}

Mengacu kepada kajian diatas bisa disimpulkan yaitu penyelenggaraan supervisi akademik pengawas sekolah di SMP Negeri 228 Jakarta tidak berjalan sebagaimana mestinya. Masih banyak hal yang perlu ditingkatkan apalagi pada masa sekarang ini yang memaksa kegiatan belajar mengajar diselenggarakan melalui pembelajaran online.

Kemudian profesionalisme guru SMP Negeri 228 Jakarta mempunyai tingkat pengetahuan yang tidak sama tentang kualifikasi sebuah pendidikan, penguasaan materi dan metode serta strategi yang dipakai pada pembelajaran online. Supervisi akademik pengawas sekolah di SMP Negeri 228 Jakarta kurang mampu meningkatkan profesionalisme, proses yang sulit dalam supervisi akademik pada pembelajaran jarak jauh. Sehingga perlu adanya sinergi antara pengawas, kepala sekolah dan juga guru-guru dalam meningkatkan profesionalismenya. Guru bukan hanya saja mendapatkan pengetahuan tentang administrasi kelas saja, namun mengenai strategi yang tepat dalam mendidik dan membimbing siswa di masa sekarang.

Terdapat beraneka ragam masukan yang bisa disampaikan menurut hasil penelitian antara lain: 1) pelaksanaan supervisi akademik pengawas satuan pendidikan di masa pandemi Covid-19 yang mencakup pembinaan, pemantauan dan penilaian serta bimbingan profesionalitas guru sebaiknya dilakukan dengan sesuai jadwal, sistematis dan berkesinambungan; 2) profesionalitas guru pada bidang penguasaan materi, cara mengelola kelas, cara menggunakan media dan sumber pengajaran sesuai di masa pandemi Covid-19.

\section{PUSTAKA ACUAN}

Daryanto, D. (2009). Panduan proses pembelajaran kreatif dan inovatif. Jakarta: Publisher.

Robbins, S. P., \& Coulter, M. (2010). Manajemen. Alih Bahasa: Bob Sabran dan Devri Barnadi Putera. Jilid 1. Edisi Kesepuluh. Erlangga. Jakarta.

Sagala, S. (2010). Supervisi Pembelajaran dalam profesi pendidikan. Bandung: Alfabeta.

Sardiman, A. M. (2020). Interaksi \& motivasi belajar mengajar.

Sudjana, N., \& Dharma, S. (2011). Buku Kerja Pengawas Sekolah. Pusat Pengembangan Tenaga Kependidikan, Badan PSDM Dan PMP. Jakarta: Kementerian Pendidikan Dan Kebudayaan.

Sugiono, S. (2011). Metode Penelitian Kombinasi (Mixed Methods). Bandung: Alfabeta.

Sugiyono, P. (2011). Metodologi penelitian kuantitatif kualitatif dan R\&D. Alpabeta, Bandung.

Sugiyono, P. (2015). Metode penelitian kombinasi (mixed methods). Bandung: Alfabeta, 28, 1-12.

Undang-Undang Nomor 20 Tahun 2003 Tentang Sistem Pendidikan Nasional Republik Indonesia.

Usman, M. (2002). Uzer, Menjadi Guru Profesional. Bandung: Rosdakarya. 